\title{
Exploring Opportunities: Optimizing Production Planning by Factoring in Energy Procurement and Trading Options
}

\author{
Maximilian Selmair ${ }^{1 *}$, Marc Hanfeld ${ }^{2}$, Thorsten Claus ${ }^{1}$, Frank Herrmann ${ }^{3}$ \\ ${ }^{1}$ International Institute Zittau, Central Academic Unit of Dresden Technical University, 02763 Zittau, Germany \\ *maximilian.selmair@mailbox.tu-dresden.de \\ ${ }^{2}$ Wintershall Holding $\mathrm{GmbH}, 34119$ Kassel, Germany \\ ${ }^{3}$ Ostbayerische Technische Hochschule, 93025 Regensburg, Germany
}

SNE 27(2), 2017, 97 - 103, DOI: 10.11128/sne.27.tn.10375

Received: May 25, 2017,

Accepted: June 10, 2017 (Special Issue Review)

SNE - Simulation Notes Europe, ARGESIM Publisher Vienna

ISSN Print 2305-9974, Online 2306-0271, www.sne-journal.org

Abstract. Motivated by the increasing share of renewable energy in the markets for energy commodities, this study has evaluated the potential for optimizing production planning by taking into account disposable options for procuring energy, in this case electricity. For this purpose, a material flow simulation study extended by an electricity price simulation has been executed to examine possible cost scenarios. Our findings support the notion of a potential for further research in new optimization models involving energy procurement as well as energy trading options.

\section{Introduction}

The nuclear phase-out, planned to have been accomplished by 2022, leads Germany to its pioneering role in expanding renewable energies. Along with the liberalization of the European energy markets, new opportunities of energy procurement have been established. Considering the remarkable volatility of the electricity market due to the increasing solar- and wind power feed-in along with individual pricing structures, the application of such opportunities imposes a flexibilization of production [1]. Thus, the authors saw the need to develop new approaches for production planning.

Based on the executed simulation study, the dependencies between production planning and energy costs are demonstrated. The results suggest that the integration of energy trading and production planning is likely to result in a monetary advantage for the manufacturing industry.
In the following sections, an investigation by means of simulation, a detailed discussion of the associated results and perspectives for future research are provided.

\section{Related Literature}

Energy-efficient production planning has become an increasingly important issue in recent years. For Germany in particular, the scheduled shutdown of nuclear power plants has raised awareness regarding resource efficient production.

Research in the field of energy efficiency and energy oriented production planning has become increasingly important in the past decade. Motivated by scarce resources, flexible energy prices and the fluctuating supply of renewable energy, there are several contributions for energy-oriented production control such as [1-13].

As not every production facility is suitable for this kind of energy orientated production planning, Kabelitz et al. [14] developed a method to evaluate the energetic flexibility of production systems.

Another way to exploit the fluctuating supply of renewable energy is the integration of energy storages. Atabay et al. [15] provided a mathematical calculation for determining the size of energy storages required, depending on the energy demand and the expected energy tariff. A case study performed in two very different companies demonstrates the application of this method.

One outstanding example for knowledge transfer between theory and practice is a project named Green Factory Bavaria which is co-operated by the Fraunhofer Society [16]. 
By providing several research, demonstration and learning platforms, the project assists the manufacturing industry in increasing their level of resource efficiency. Technical solutions as well as methodical approaches are part of the knowledge transfer from applied research to the manufacturing industry.

However, approaches taking into account financial possibilities in energy procurement for the purpose of optimizing production planning have not been developed yet. The following section describes the authors' proposal of such an approach.

\section{Problem Definition}

In recent years, the energy market's structure has been changed by liberalization, energy transition and digitalization. The formation of wholesale markets for energy and the developing competition provides opportunities to trade amounts of energy among market participants. This also enables non-energy companies to benefit from the energy trading opportunities. The trading of energy can be organized by institutional exchanges (e.g. European Energy Exchange EEX or Intercontinental Exchange ICE) or may be based on bilateral negotiations. Manufacturing companies, whose production processes are very energy intensive, can obtain their energy requirements directly or indirectly via an upstream supplier by trading standardized products in the markets for electricity and gas.

These standardized products that can be traded on the spot and futures markets include baseload volumes of various maturities. The following contract types can be differentiated:

- hourly contracts

- daily contracts

- monthly contracts

- quarterly contracts

- seasonal contracts

- yearly contracts

For instance, within an hourly contract a constant load will be delivered for a fixed price (e.g. $1 \mathrm{MWh} / \mathrm{h}$ for $25 € / \mathrm{MWh})$. The commodity electricity can be divided into baseload- and peak load contracts. The same is applicable for monthly contracts, where a constant load is supplied for all hours of a month - just as for the quarters, seasons and years. The prices for the different contract types are subjected to price variations at the respective trading times.
The different products are being traded in different maturities. For example, on the electricity market of the EEX it is only possible to trade contracts with delivery of single hours of a given day on that particular day (intraday trading); the trading of daily deliveries is only possible on the day prior. Monthly contracts are traded a few months prior to their delivery.

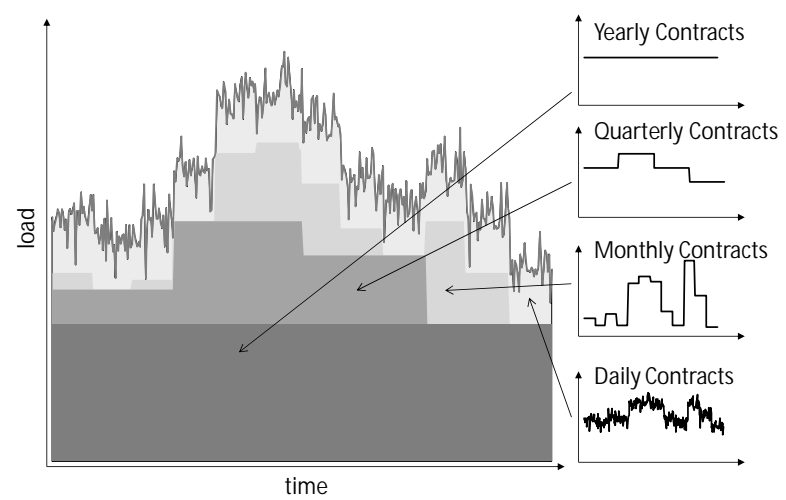

Figure 1: Structuring of a load profile using standardized energy trading products.

The same applies respectively for quarterly, seasonal and yearly contracts. In practice, the scheduled purchase of energy is based on historical load profiles. The principle that underlies the structure of an exemplary load profile with the above mentioned standardized products is illustrated in Figure 1.

Interdependencies between production planning and energy trading can be identified $[15,17]$. One possibility to influence the energy costs is an advantageous combination of the standard trading products and the best moment to buy commodity products. In other words: When the prices are high, a low demand is advisable and vice versa. Therefore, it will be an advantage to place high-demand-periods in low-priceperiods.

Nevertheless, manufacturing companies that participate in energy trading markets are faced with cost associated risks. These risks result from the markets' price volatility and have to be supervised. In this discussion, we define the cost risk as the deviation between the planned budget and actual costs. Therefore, a high variance of the energy demand would lead to greater cost risks. If a high degree of capacity utilization of the production is achieved in the early stages of planning, the resulting load profile can almost completely be structured by forward based contracts. 
Thus, it is possible to secure energy prices in advance and - due to the absence of (unplanned) short term load variations - to avoid the selling / buying of short term (hourly) contracts and to reduce the cost risk. The following figure illustrates these relationships.

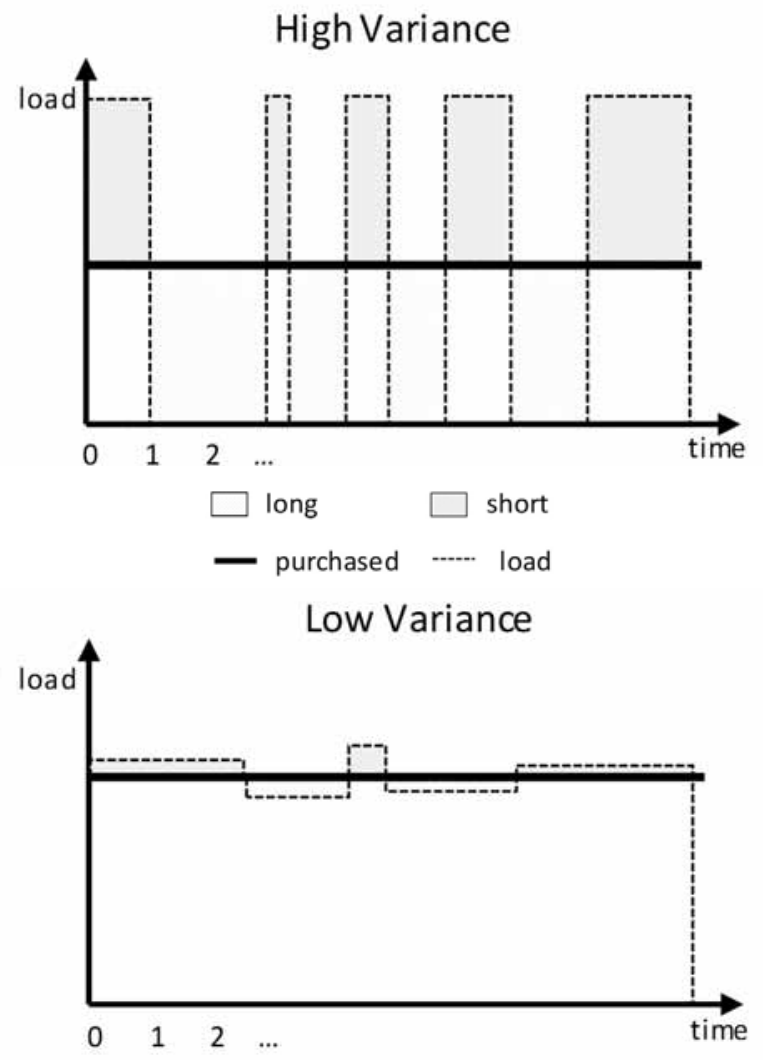

Figure 2: Dependence of load profile variance and energy purchasing.

\begin{tabular}{lrrr}
\hline $\mathbf{T}$ & $\begin{array}{r}\text { Scen 1 } \\
\text { [ध/Uo/M] }\end{array}$ & $\begin{array}{r}\text { Scen 2 } \\
{[\boldsymbol{\epsilon} / \mathrm{UoM}]}\end{array}$ & $\begin{array}{r}\text { Scen 3 } \\
{[\boldsymbol{\epsilon} / \mathrm{UoM}]}\end{array}$ \\
\hline $\mathbf{0}$ & 30.00 & 30.00 & 30.00 \\
\hline $\mathbf{1}$ & 31.49 & 29.64 & 41.84 \\
\hline $\mathbf{2}$ & 24.51 & 24.96 & 46.33 \\
\hline $\mathbf{3}$ & 29.26 & 24.97 & 49.02 \\
\hline $\mathbf{4}$ & 25.60 & 29.93 & 41.68 \\
\hline $\mathbf{5}$ & 16.50 & 28.72 & 50.82 \\
\hline $\mathbf{6}$ & 16.25 & 21.56 & 50.88 \\
\hline
\end{tabular}

Table 1: Price scenarios.
The first chart of Figure 2 depicts the fictitious case of a production plan with a high variance load profile. This case results in high load fluctuations. If a forward contract was to be purchased at $t=0$, time periods with shortages and with surplus quantities would result. At the beginning of the planning period, the exact prices for selling surplus or buying shortfall quantities are unknown. Consequently, a cost risk results.

The second chart describes low variance. If the energy procurement is planned on the basis of this load profile, only small deviations remain, which can be evened out by means of short term trading products. This results in a lower cost risk in comparison to the scenario in the first chart.

The numerical example below illustrates the problem regarding the dependency of costs for energy and production planning. The above-mentioned cases are the basis for the following: (1) The production plan results in high variance of the energy load profile and (2) low variance of the energy load profile. The planning period amounts to $6 \mathrm{TU}$ (time units). At the beginning of the planning period $(t=0)$, a baseload contract for these $6 \mathrm{TU}$ is worth $30 € / \mathrm{UoM}$ (Units of Measurement) (delivery across all $6 \mathrm{TU}$ ). Purchasing a baseload contract for this period is only possible in $t=0$. Table 1 provides three price scenarios that represent possible price trends when purchasing short-term contracts.

Table 2 displays case (1) with high variance. For demonstration purposes, it is assumed that 3 UoM must be produced in total and each product UoM requires $1 \mathrm{UoM}$ of energy. Thus, in $\mathrm{t}=0$ it is only possible to purchase a baseload contract for the next $6 \mathrm{TU}$. In this example, the baseload contract is determined by 0.5 UoM. In this case, the initial production plan specifies the production of $1 \mathrm{UoM}$ in periods $t=\{1,4,5\}$ respectively. Due to the purchasing of energy with a load of $0.5 \mathrm{UoM}$ in $\mathrm{t}=0$, in $\mathrm{t}=\{2,3,6\}$, surplus quantities occur. These quantities are sold on the market at the prices mentioned in Table 1. Consequently, shortages arise in $\mathrm{t}=\{1,4,5\}$ that need to be procured at prices which also listed in Table 1 The distribution of costs displayed below in Table 2 results from the scenario of the planning point in $\mathrm{t}=0$.

Based on this example, the energy costs are subject to variations. Depending on the price development, the costs range from $€ 84,05$ to $€ 98,39$. 


\begin{tabular}{lrrrrrr}
\hline $\mathbf{t}$ & $\begin{array}{r}\text { Load } \\
\text { [UolM] }\end{array}$ & $\begin{array}{r}\text { Purchase } \\
\text { [UoM] }\end{array}$ & $\begin{array}{r}\text { +long/ } \\
\text { - short } \\
\text { [UolM] }\end{array}$ & $\begin{array}{r}\text { Scen 1 } \\
\text { [€] }\end{array}$ & $\begin{array}{r}\text { Scen 2 } \\
\text { [€] }\end{array}$ & $\begin{array}{r}\text { Scen 3 } \\
\text { [€] }\end{array}$ \\
\hline $\mathbf{1}$ & 1 & 0.5 & -0.5 & -30.75 & -29.82 & -35.92 \\
\hline $\mathbf{2}$ & 0 & 0.5 & 0.5 & -2.75 & -2.52 & 8.16 \\
\hline $\mathbf{3}$ & 0 & 0.5 & 0.5 & -0.37 & -2.51 & 9.51 \\
\hline $\mathbf{4}$ & 1 & 0.5 & -0.5 & -27.80 & -29.96 & -35.84 \\
\hline $\mathbf{5}$ & 1 & 0.5 & -0.5 & -23.25 & -29.36 & -40.41 \\
\hline $\mathbf{6}$ & 0 & 0.5 & 0.5 & -6.88 & -4.22 & 10.44 \\
\hline & & & $\mathbf{\Sigma}$ & $\mathbf{- 9 1 8 0}$ & $\mathbf{- 9 8 . 3 9}$ & $\mathbf{- 8 4 . 0 6}$ \\
\hline
\end{tabular}

Table 2: Cost distribution for a high-variance-load-profile.

In the following section, the scenario for case (2) is discussed. The initial production plan results in an even distribution of the 3 UoM over the $6 \mathrm{TU}$. This results in a load profile of $0.5 \mathrm{UoM} / \mathrm{TU}$, which is purchased as a baseload contract in $t=0$, results (see Table 3 ). Thus, the load variations in the planning period as well as the necessity to sell/buy surplus/shortfall quantities are reduced to a minimum.

Therefore, the load profile can be covered entirely by purchasing the baseload contract in $t=0$ and the price of $30 € / \mathrm{UoM}$ can be secured. The overall costs for purchasing energy amounts $€ 90$ in every of the three price scenarios (see Table 3 ). In this case, there are no cost variations and the costs in every price scenario are the same.

As illustrated in the above-mentioned example cases, it is likely that an integrated view of production planning and energy purchasing will influence energy costs. On the one hand, the forward markets' opportunities for securing energy prices, and on the other hand, the trading of short-term contracts on the spot market provides a potential for optimizing the flexibility of the production process and for reducing the costs for energy.

The main target of this contribution is the implementation of a simulation study. Therewith, the impact of an integrated view of production planning in combination with the opportunities of energy trading on the expense situations of companies can be conjectured. Finally, the optimization potential is identified and the determinants of the optimization problem are specified.

\begin{tabular}{lrrrrrr}
\hline $\mathbf{t}$ & $\begin{array}{r}\text { Load } \\
\text { [UolM] }\end{array}$ & $\begin{array}{r}\text { Purchase } \\
\text { [UolM] }\end{array}$ & $\begin{array}{r}\text { +long/ } \\
\text { - short } \\
\text { [UolM] }\end{array}$ & $\begin{array}{r}\text { Scen 1 } \\
\text { [€] }\end{array}$ & $\begin{array}{r}\text { Scen 2 } \\
\text { [€] }\end{array}$ & $\begin{array}{r}\text { Scen 3 } \\
\text { [€] }\end{array}$ \\
\hline $\mathbf{1}$ & 0.5 & 0.5 & 0 & -15.00 & -15.00 & -15.00 \\
\hline $\mathbf{2}$ & 0.5 & 0.5 & 0 & -15.00 & -15.00 & -15.00 \\
\hline $\mathbf{3}$ & 0.5 & 0.5 & 0 & -15.00 & -15.00 & -15.00 \\
\hline $\mathbf{4}$ & 0.5 & 0.5 & 0 & -15.00 & -15.00 & -15.00 \\
\hline $\mathbf{5}$ & 0.5 & 0.5 & 0 & -15.00 & -15.00 & -15.00 \\
\hline $\mathbf{6}$ & 0.5 & 0.5 & 0 & -15.00 & -15.00 & -15.00 \\
\hline & & & $\mathbf{\Sigma}$ & $\mathbf{- 9 0 . 0 0}$ & $\mathbf{- 9 0 . 0 0}$ & $\mathbf{- 9 0 . 0 0}$ \\
\hline
\end{tabular}

Table 3: Cost distribution for a low-variance-load-profile.

\section{Simulation Study}

This section describes the details of the parameters utilized in the simulation study. Figure 3 illustrates the resulting energy cost distribution as a result of merging a material flow simulation and an electricity price simulation. Both mentioned simulations are independent of one another.

Material Flow Simulation. The requirement for this part of the simulation was to determine a complete energy consumption pattern for a fictitious production system. For this purpose, a job shop production system with a total number of nine machines was designed. In order to examine different consumption patterns, it was decided to apply different priority rules when scheduling this production system. Such heuristic methods are used in industrial practice to avoid timeconsuming constraint-based approaches. Although these methods have nothing in common with energy saving methods, they can be used to obtain different energy patterns.

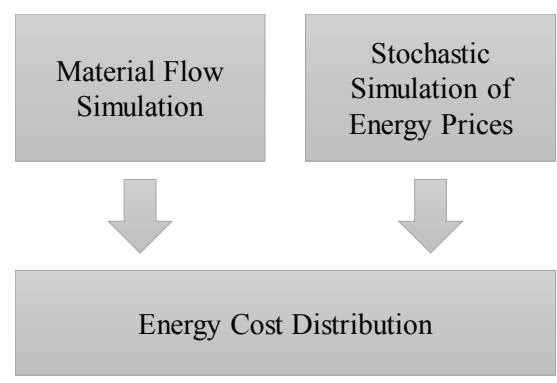

Figure 3: Proceeding of the simulation study. 
Commonly applied rules are as follows [18]:

- FIFO: First-In-First-Out

- LIFO: Last-In-First-Out

- SJF: Shortest Job First

- LJF: Longest Job First

- SRPT: Shortest Remaining Processing Time

- LRPT: Longest Remaining Processing Time

- EDD: Earliest Due Date

With a flow simulation model designed in Tecnomatix Plant Simulation 13, these seven rules for the same volume of orders were applied to generate different consumption patterns. As the total consumption of the production system is the point of interest, the energy patterns of all machines are identical:

- Ramp Up: $10 \mathrm{~kW} / \mathrm{h}$

- Setup: $\quad 7 \mathrm{~kW} / \mathrm{h}$

- Processing: $35 \mathrm{~kW} / \mathrm{h}$

- Standby: $6 \mathrm{~kW} / \mathrm{h}$

- Ramp Down: $7 \mathrm{~kW} / \mathrm{h}$

The case study includes a total amount of 810 jobs. Every job is linked to a working schedule specified by one of four possible products that is to be produced. This sequence can be inferred from Figure 4. All durations are stated in minutes.

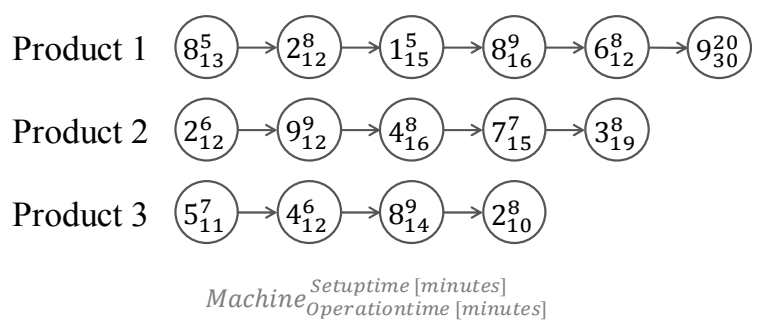

Figure 4: Sequence, setup time and operation time for each product.

The order quantity of each job is an evenly distributed number between 2 and 6 . Depending on the applied priority rule, processing these jobs will take between 33 and 36 days. This algorithm to create all 810 jobs is given in the pseudocode shown next.

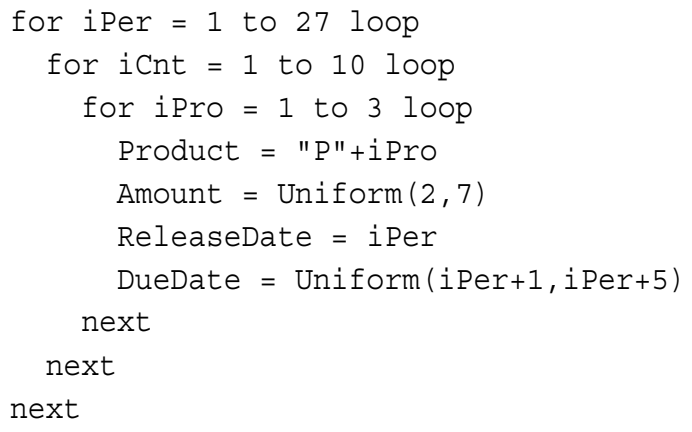

Listing 1: Algorithm for job-compiling.

The algorithm generates jobs for 27 periods (first loop). Every period contains 10 jobs (second loop) for each product (third loop).

Price Simulation. The Ornstein-Uhlenbeck-Process was used to model and simulate the stochastic behavior of electricity price developments. This approach is in line with [19] as a base model for commodity prices:

$$
d S=\kappa(\mu-S) d t+\sigma d Z
$$

Parameters are described as follows:

- S: Electricity Spot Price

- $\kappa:$ Mean Reversion Factor

- $\mu$ : Mean (e.g. price of forward contracts)

- dZ: Brownian Motion

- $\sigma$ : Standard deviation of the price returns

- dt: Time increment

As the historical spot prices for electricity contain negative prices, the logarithm of the prices discussed by Schwartz [19] is not applicable. Therefore, the naive discretized approach, mentioned in [20], was applied when simulating the electricity spot prices:

$$
S_{t}=S_{t-1}+\kappa\left(\mu-S_{t-1}\right) \Delta t+\sigma d Z_{t}
$$

The process simulation was based on the following parameter values:

- $\mathrm{S}_{\mathrm{t}=0}: 24.21$

- $\kappa: 0.0736$

- $\mu: 25$

- $\sigma: 4.7051$

- $\Delta \mathrm{t}: 1$ 
Using the model mentioned above, 1,000 price paths for a period from 01/05/2016 0:00 till 05/06/2016 20:00 was simulated. The simulated price paths are negative in some cases. That is, in these periods a company would receive money when obtaining energy from the supplier.

For the purpose of simplification and reproducibility of the results, we refrained from using a more complex model. For an extended spot price model see [17].

\section{Results}

In this section, closer look at the results of the above described simulations and the resulting energy cost distribution is presented. A different load profile was generated for each applied priority rule, as visualized in Figure 5. The combination of these load profiles with 1,000 random price paths leads to Figure 6. Here, the cost distributions for every applied priority rule are evaluated.

It is noticeable that all distributions are different regarding their expected value and spread. Thus, in this case study, some priority rules such as LRPT or FIFO lead to lower expected energy costs than others. Another important indicator is the spread of the cost distribution. The wider the distribution, the higher is the uncertainty and thus the resulting cost risk. Therefore, the EDD rule provides the narrowest distribution and thus the lowest uncertainty. Depending on the market's energy prices, the costs for obtaining energy can deviate more from the expected value if the distribution is widespread. All cost distributions are described detailed with estimated costs, minimum, maximum, spread and an exemplary historical value in Table 4.

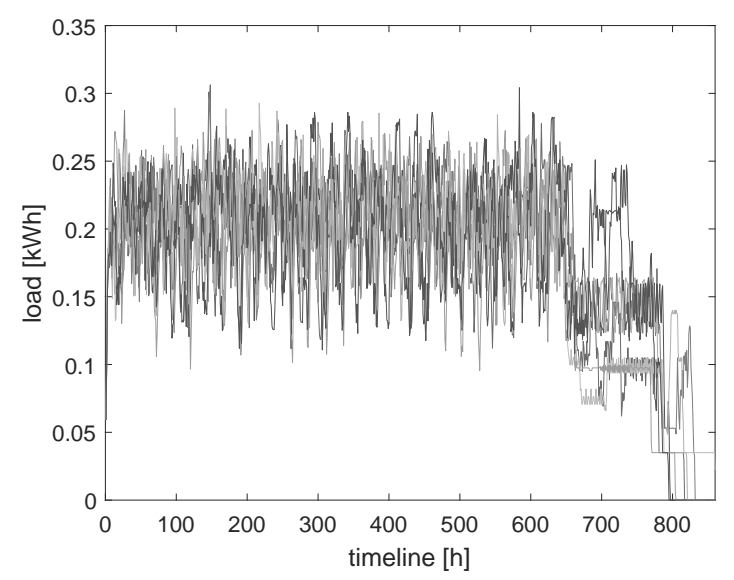

Figure 5: Load profile for applied priority rules.
The various distributions, especially their deviations, provide a potential for using energy procurement and trading options to minimize energy costs in industrial manufacturing. The application of seven different priority rules for scheduling the production system of our case study leads to different and random procurement times.

As can be seen in Figure 6 and read in more detail in Table 4 , the resulting costs and also the resulting cost uncertainty differs between all cases. This implies a cost sensitivity regarding a) the combination of contracts in the forward market, which can be bought at the beginning $(t=0)$ and should be adjusted during the production period depending on the price development for the tradeable forward contract and $b$ ) the reaction of short term price movements on the spot market.

Using this potential requires a suitable planning approach and should be object of further research.

\begin{tabular}{rrrrrr}
\hline $\begin{array}{r}\text { Prionity Expected Min [€] Max [€] Spread [€] Hist.* [€] } \\
\text { Rule } \\
\text { Costs[€] }\end{array}$ & & & & \\
\hline HFO & 3.753 & 3.500 & 4.014 & 514 & 3.757 \\
\hline UFO & 3.863 & 3.662 & 4.061 & 400 & 3.873 \\
\hline SF & 3.748 & 3.389 & 4.120 & 731 & 3.671 \\
\hline UF & 3.841 & 3.709 & 3.977 & 268 & 3.830 \\
\hline SRPT & 3.854 & 3.694 & 4.037 & 343 & 3.878 \\
\hline IRPT & 3.660 & 3.381 & 3.944 & 563 & 3.608 \\
\hline BDD & 3.823 & 3.690 & 3.984 & 293 & 3.781 \\
\hline *historical value from $01 / 05 / 2016$ & & &
\end{tabular}

Table 4: Description of all cost distribution.

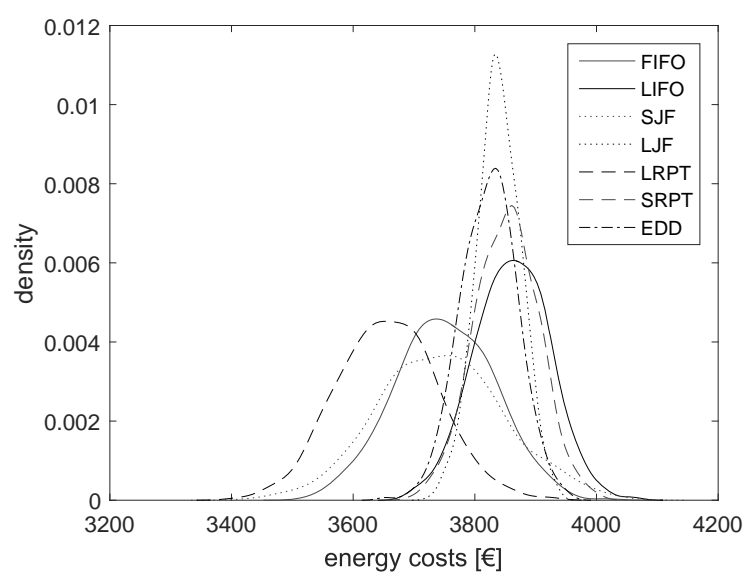

Figure 6: Energy cost distributions for applied priority rules. 


\section{Conclusion and Future Work}

In this investigation, potential for augmenting the optimization of production planning by factoring in energy procurement and trading options was identified. Provided that a company's production offers enough flexibility, short-term reactions to changing market situations are possible. By means of our simulation study, our results are demonstrating different energy costs distributions for a variety of schedules generated by applying common priority rules. Consequently, a potential for optimization is apparent.

Therefore, an optimization model that focuses on saving energy costs in periods in which the production schedule is flexible will be our objective for further research. While planning continuously, the model should re-plan the whole planning horizon after each period to consider short-term as well as long-term energy price changes. Thus, an inclusion to the hierarchical production planning concept provided by Hax and Meal [21] seems appropriate to the authors.

Finally, we want to highlight that this research project does not focus on a higher energy efficiency and will not save energy in particular. Rather, it should help to reduce energy costs and decrease the cost risk for companies without fixed energy prices by means of an integrated consideration of energy procurement and trading options.

\section{References}

[1] Rackow T, Kohl J, Canzaniello A, Schuderer P, Franke J. Energy Flexible Production: Saving Electricity Expenditures by Adjusting the Production Plan. Procedia CIRP. 2015. 235-240.

[2] Thiede, S. Energy efficiency in manufacturing systems. Berlin: Springer. 2012. 198 p.

[3] Schultz C, Sellmaier P, Reinhart G. An Approach for Energy-oriented Production Control Using Energy Flexibility. Procedia CIRP. 2015. 197-202.

[4] Keller F, Reinhart G. Energy Supply Orientation in Production Planning Systems. Procedia CIRP. 2016. 244249.

[5] Selmair M, Herrmann F, Claus T, Teich E. Potentiale in der Reduzierung des Gesamtenergieverbrauchs einer Werkstattfertigung in der Maschinenbelegungsplanung. In: Selmair M, Herrmann F, Claus T, Teich E. Simulation in Production and Logistics 2015, 2015. Rabe M, Clausen U. 575-584.

[6] Beier J, Neef B, Thiede S, Herrmann C. Integrating onsite Renewable Electricity Generation into a Manufacturing System with Intermittent Battery Storage from Electric Vehicles. Procedia CIRP. 2016. 483-488.
[7] Frigerio N, Matta A. Energy Efficient Control Strategy for Machine Tools with Stochastic Arrivals and Time Dependent Warm-up. Procedia CIRP. 2014. 56-61.

[8] Frigerio N, Matta A. Analysis of an Energy Oriented Switching Control of Production Lines. Procedia CIRP. 2015. 34-39.

[9] Greinacher S, Lanza G. Optimisation of Lean and Green Strategy Deployment in Manufacturing Systems. AMM. 2015. 478-485.

[10] Putz M, Schlegel A, Stoldt J, Franz E, Langer T. Energysensitive control strategies for decoupled production systems. International Journal of Sustainable Manufacturing. 2014; 3. 250-268.

[11] Stoldt J, Schlegel A, Franz E, Langer T, Putz M. Generic Energy-Enhancement Module for Consumption Analysis of Manufacturing Processes in Discrete Event Simulation. In: Stoldt J, Schlegel A, Franz E, Langer T, Putz M. Re-engineering Manufacturing for Sustainability, 2013. Nee A Y C, Song B, Ong S-K. 165-170.

[12] Stoldt J, Schlegel A, Putz M. Enhanced integration of energy-related considerations in discrete event simulation for manufacturing applications. Journal of Simulation. 2016; 2. 113-122. doi: 10.1057/jos.2015.24.

[13] Suwa H, Samukawa T. Research and Innovation in Manufacturing: Key Enabling Technologies for the Factories of the Future - Proceedings of the 48th CIRP Conference on Manufacturing Systems A New Framework of Energy-efficient Manufacturing Systems Based on Energy Load Profiles. Procedia CIRP. 2016. 313-317.

[14] Kabelitz S, Streckfuß U, Gujjula R. Einsatz von mathematischen Optimierungsverfahren zur energieorientierten Produktionsplanung. 2014.

[15] Atabay D, Dornmair R, Hamacher T, Keller F, Reinhart G. Flexibilisierung des Stromverbrauchs in Fabriken. 2014.

[16] Gebbe C, Hilmer S, Götz G, Lutter-Günther M, Chen Q, Unterberger E, Glasschröder J, Schmidt V, Riss F, Kamps T, Tammer C, Seidel C, Braunreuther S, Reinhart G. Concept of the Green Factory Bavaria in Augsburg. Procedia CIRP. 2015. 53-57.

[17] Müller A, Burger M, Klar B, Schindlmayr G. A spot market model for pricing derivatives in electricity markets. Quantitative Finance. 2004; 1. 109-122.

[18] Panwalkar SS, Iskander W. A Survey of Scheduling Rules. Operations Research. 1977; 1. 45-61.

[19] Schwartz, ES. The stochastic behavior of commodity prices. The journal of the American Finance Association. 1997.

[20] Smith, W. On the simulation and estimation of the meanreverting Ornstein-Uhlenbeck process. Commodities Markets and Modelling. 2010.

[21] Hax AC, Meal HC. Hierarchical integration of production planning and scheduling. 1973. 
